\title{
Identification of molecular candidates and interaction networks via integrative toxicogenomic analysis in a human cell line following low-dose exposure to the carcinogenic metals cadmium and nickel
}

\author{
JEE YOUNG KWON ${ }^{1,2^{*}}$, JONG-IL WEON $^{3 *}$, PREEYAPORN KOEDRITH ${ }^{4}$, \\ KANG-SIK PARK ${ }^{5}$, IM SOON KIM ${ }^{6}$ and YOUNG ROK SEO ${ }^{1}$ \\ ${ }^{1}$ Department of Life Science, Institute of Environmental Medicine for Green Chemistry, Dongguk University, Seoul 100-715; \\ ${ }^{2}$ Department of Biomedical Science, School of Medicine, Kyung Hee University, Seoul 130-701; ${ }^{3}$ Department of \\ Safety Engineering, Institute of Environmental Medicine for Green Chemistry, Dongguk University, Gyeongju, \\ Gyeongbuk 780-714, Republic of Korea; ${ }^{4}$ Faculty of Environment and Resource Studies, Mahidol University, \\ Phuttamonthon District, NakhonPathom 73170, Thailand; ${ }^{5}$ Department of Physiology, and Biomedical \\ Science Institute, Kyung Hee University School of Medicine, Seoul 130-701; ${ }^{6}$ Graduate School \\ of Environmental Studies, Kwangwoon University, Seoul 139-701, Republic of Korea
}

Received March 13, 2013; Accepted May 16, 2013

DOI: $10.3892 /$ or.2013.2587

\begin{abstract}
Cadmium and nickel have been classified as carcinogenic to humans by the World Health Organization's International Agency for Research on Cancer. Given their prevalence in the environment, the fact that cadmium and nickel may cause diseases including cancer even at low doses is a cause for concern. However, the exact mechanisms underlying the toxicological effects induced by low-dose exposure to cadmium and nickel remain to be elucidated. Furthermore, it has recently been recognized that integrative analysis of DNA, mRNA and proteins is required to discover biomarkers and signaling networks relevant to human toxicant exposure. In the present study, we examined the deleterious effects of chronic low-dose exposure of either cadmium or nickel on global profiling of DNA copy number variation, mRNA and proteins. Array comparative genomic hybridization, gene expression microarray and functional proteomics were conducted, and a bioinformatics tool, which predicted signaling pathways, was applied to integrate data for each heavy metal separately and together. We found distinctive signaling networks associated with subchronic low-dose exposure to cadmium and nickel, and identified pathways common to both. ACTB, HSP90AA1,
\end{abstract}

Correspondence to: Dr Young Rok Seo, Department of Life Science, Institute of Environmental Medicine for Green Chemistry, Dongguk University, Seoul 100-715, Republic of Korea

E-mail: seoyr@dongguk.edu

${ }^{*}$ Contributed equally

Key words: cadmium, carcinogenesis, heavy metal, nickel, pathway analysis, toxicogenomics
HSPA5 and HSPA8, which are key mediators of pathways related to apoptosis, proliferation and neoplastic processes, were key mediators of the same pathways in low-dose nickel and cadmium exposure in particular. CASP-associated signaling pathways involving CASP3, CASP7 and CASP9 were observed in cadmium-exposed cells. We found that HSP90AA1, one of the main modulators, interacted with HIF1A, AR and BCL2 in nickel-exposed cells. Interestingly, we found that HSP90AA1 was involved in the BCL2-associated apoptotic pathway in the nickel-only data, whereas this gene interacted with several genes functioning in CASP-associated apoptotic signaling in the cadmium-only data. Additionally, JUN and FASN were main modulators in nickel-responsive signaling pathways. Our results provide valuable biomarkers and distinctive signaling networks that responded to subchronic low-dose exposure to cadmium and nickel.

\section{Introduction}

Toxic heavy metals including cadmium and nickel, which are common contaminants in occupational and environmental areas, may contribute to harmful effects on humans and other organisms. Unsafe persistent exposure to such metals is mediated through oral intake of contaminated water and food, inhalation of polluted air, or dermal contact from manufacturing processes and environmental contamination. Indeed, deleterious health effects caused by cadmium and nickel are similar, but the underlying mechanisms of toxicity and biological/toxicological signaling pathways are individually different (1-3).

Cadmium is a natural constituent of ocean water and the earth's crust and is commonly associated with zinc, lead and copper ores (4). Due to its physicochemical properties, it is utilized in a variety of ways, such as in batteries, pigment, 
coating, plating, plastic stabilizers, non-ferrous alloys and photovoltaic devices. Ingestion of contaminated food and water and inhalation by active and passive smoking are considered the predominant routes for cadmium exposure (5). Cadmium is classified as carcinogenic to humans (group 1) by the World Health Organization's International Agency for Research on Cancer, as it acts as an epigenetic or indirect genotoxic element. The molecular mechanisms of cadmium carcinogenicity have been recently reviewed (6-8) and range from interference with thiol-containing proteins and consequent induction of oxidative stress to genomic expression changes triggering cell cycle arrest, apoptosis, differentiation and immortalization. Strong data from epidemiological studies on occupational populations related to cadmium carcinogenicity showed that lung cancer occurs by breathing the metal (9). Cadmium affects the transcription of several genes; it induces protective genes, including those coding for metallothioneins with a cadmiumchelating property $(10,11)$, heat shock proteins (HSPs) with roles in protein renaturation $(12,13)$ and heme-oxygenase I with an anti-oxidative role (14). Notably, cadmium may induce proto-oncogenes $(15,16)$ which can contribute to carcinogenesis. Its effects on the sex hormone receptor genes (17) also suggest endocrine-disrupting activity. However, these effects of cadmium on gene expression are only a fraction of the effects, and the unidentified effects on gene functioning in toxicity and protection against cadmium must be clarified.

Nickel, a non-essential metal, occurs naturally in soils and volcanic dust. It also has been categorized as a carcinogenic heavy metal by the World Health Organization's International Agency for Research on Cancer. It combines with other metals to form alloys that are widely used to produce coins, jewelry and stainless steel. Nickel compounds are also applied to refining, electroplating, welding, color pigmentation in ceramics, the production of batteries, medical devices and carbon particles (18). Although several animal epidemiological and cell culture studies have documented that nickel compounds are carcinogenic; the molecular mechanisms of nickel carcinogenicity have not been investigated (19-22). The mutagenic activity of nickel compounds to mammalian cells in vitro in the Salmonella mutation assay was found to be low, indicating that nickel-mediated mutagenic activity is not the definite mechanism underlying nickel carcinogenicity $(23,24)$. A number of studies have implicated that aberrant modification of structural chromatin and epigenetic alterations might be the predominant contributable factors to nickel carcinogenesis.

Both cadmium and nickel have adverse effects on human health by inducing oxidative stress, inhibiting DNA repair proteins, and dysregulating signal transduction, thereby leading to aberrant cell proliferation and differentiation (3). Furthermore, they have also been associated with an increased risk for diseases, including cancer, following chronic low-dose exposure $(25,26)$. However, activation of these pathways still remains to be elucidated. In the present study, we comprehensively explored molecular candidates and the mechanisms of toxicity, both common and distinct, for nickel and cadmium using integrative toxicogenomic and bioinformatic tools. We compared the effects of cadmium to those of nickel using comparative genomic hybridization $(\mathrm{CGH})$ array, gene expression microarray and functional proteomics-based technologies in p53-proficient human colon carcinoma RKO cells. The cells were subchronically exposed to low levels of cadmium chloride or nickel acetate, based on a survival rate of at least $80 \%$ after a $24-\mathrm{h}$ treatment. We also identified both common and distinct mechanisms of toxicity underlying the individual metals. Similarities and differences in gene expression profiles, respective pathways and biological processes following lowlevel exposure to each metal are also discussed.

\section{Materials and methods}

Cell culture and treatment. Human RKO colon carcinoma cells (ATCC no. CRL-2577) were cultured in RPMI-1640 (Gibco, Grand Island, NY, USA) supplemented with $10 \%$ fetal bovine serum (Gibco) and $1 \%$ antibiotics (Gibco) at $37^{\circ} \mathrm{C}$ and $5 \% \mathrm{CO}_{2}$. Cadmium chloride and nickel (II) acetate were purchased from Sigma Co. (St. Louis, MO, USA). The 3-(4,5-dimethylthiazol-2-yl)-2,5-diphenyltetrazolium bromide assay and fluorescence-activated cell sorting analysis were conducted to select the sublethal doses of cadmium and nickel for our experimental design. The RKO cells were exposed to $50 \mu \mathrm{M}$ cadmium and $20 \mu \mathrm{M}$ nickel for $24 \mathrm{~h}$ prior to subsequent testing.

Array comparative genomic hybridization. Genomic DNA was extracted from RKO cells treated with either metal and subjected to copy number variation (CNV) analyses using Agilent SurePrint G3 microarrays with one million-format slides (Agilent Technologies, Palo Alto, CA, USA), in accordance with the manufacturer's protocol. Briefly, DNA was labeled with the exo-Klenow fragment using random primers and cyanine 5 and cyanine 3 fluorescent-labeled nucleotides. Next, hybridization with the hybridization master mix, washing and drying were carried out. Subsequently, the microarray slides were scanned at $2-\mu \mathrm{m}$ resolution using a G2539A microarray scanner (Agilent Technologies). Features were extracted from the scanned images using Feature Extraction software (Agilent Technologies). The extracted features were analyzed using Nexus Copy Number software (BioDiscovery, El Segundo, CA, USA). Thresholds were set at a minimum of three probes and a 0.4 average log ratio.

Gene expression microarray. Total RNA was extracted with the RNeasy Mini kit (Qiagen, Hilden, Germany) according to the manufacturer's recommendations. RNA quality was assessed with an Agilent Bioanalyzer Nano Chip 2100 (Agilent Technologies). The RNA samples were then labeled using a Low Input Quick Amp Labeling kit (Agilent Technologies), in accordance with the manufacturer's protocol. Hybridization was conducted using a Gene Expression Hybridization kit (Agilent Technologies). A gene expression microarray chip was designed to perceive pathways involving DNA damage and repair, apoptosis, oxidative stress and the cell cycle. The arrays were scanned on an Agilent scanner and analyzed using Feature Extraction software. Subio platform version 1.6 was used for the transcriptomic data analysis.

Functional proteomics. Cells were collected by scrapping and were washed in PBS ( $\mathrm{pH}$ 7.4) for immunoprecipitation. After centrifugation, the cells were resuspended and homogenized in RIPA buffer [50 mM Tris- $\mathrm{HCl} \mathrm{pH} 7.8,150 \mathrm{mM}$ $\mathrm{NaCl}, 0.5 \mathrm{mM}$ EDTA, $0.1 \%$ sodium dodecyl sulfate (SDS), 
Table I. Key genes among the commonly expressed genes in cells subchronically exposed to low-level cadmium and nickel after integrative toxicogenomic analysis.

\begin{tabular}{|c|c|c|}
\hline Gene symbol & Gene ID & Gene name \\
\hline ACTB & 60 & Actin, $\beta$ \\
\hline $\mathrm{AKR} 1 \mathrm{C} 2$ & 1646 & $\begin{array}{l}\text { Aldo-ketoreductase family } 1 \text {, member } \mathrm{C} 2 \text { (dihydrodiol dehydrogenase } 2 \text {; } \\
\text { bile acid binding protein; } 3 \text { - } \alpha \text { hydroxysteroid dehydrogenase, type III) }\end{array}$ \\
\hline DCD & 117159 & Dermcidin \\
\hline HSP90AA1 & 3320 & Heat shock protein $90 \mathrm{kDa} \alpha$ (cytosolic), class A member 1 \\
\hline HSP90AB1 & 3326 & Heat shock protein $90 \mathrm{kDa} \alpha$ (cytosolic), class B member 1 \\
\hline HSPA1A (HSPA1B) & 3303 & Heat shock $70 \mathrm{kDa}$ protein $1 \mathrm{~A}$ \\
\hline HSP90B1 & 7184 & Heat shock protein $90 \mathrm{kDa} \beta$ (Grp94), member 1 \\
\hline HSPA2 & 3306 & Heat shock $70 \mathrm{kDa}$ protein 2 \\
\hline HSPA5 & 3309 & Heat shock $70 \mathrm{kDa}$ protein 5 (glucose-regulated protein, $78 \mathrm{kDa}$ ) \\
\hline HSPA8 & 3312 & Heat shock $70 \mathrm{kDa}$ protein 8 \\
\hline HSPA9 & 3313 & Heat shock $70 \mathrm{kDa}$ protein 9 (mortalin) \\
\hline IDH1 & 3417 & Isocitrate dehydrogenase $1\left(\mathrm{NADP}^{+}\right)$, soluble \\
\hline KRT18 & 3875 & Keratin 18 \\
\hline MYH7 & 4625 & Myosin, heavy chain 7 , cardiac muscle, $\beta$ \\
\hline NUDC & 10726 & Nuclear distribution C homolog (A. nidulans) \\
\hline P4HB & 5043 & Prolyl 4-hydroxylase, $\beta$ polypeptide \\
\hline PGK1 & 5230 & Phosphoglycerate kinase 1 \\
\hline PPP1R13B & 23368 & Protein phosphatase 1, regulatory subunit $13 \mathrm{~B}$ \\
\hline RNF128 & 79589 & Ring finger protein $128, \mathrm{E} 3$ ubiquitin protein ligase \\
\hline RPH3AL & 9501 & Rabphilin 3A-like (without C2 domains) \\
\hline TWIST1 & 7291 & Twist homolog 1 (Drosophila) \\
\hline UTS2 & 10911 & Urotensin 2 \\
\hline
\end{tabular}

1\% Triton X-100, $1 \mathrm{mM}$ DTT and protease inhibitor cocktail (Roche, Mannheim, Germany)]. The homogenate was incubated on ice for $30 \mathrm{~min}$ and then centrifuged at $13,000 \mathrm{rpm}$ and $4^{\circ} \mathrm{C}$ for 30 min to collect the supernatant. The samples were incubated with $4 \mu \mathrm{g}$ rabbit anti-Gadd45a antibody (Santa Cruz Biotechnology, Santa Cruz, CA, USA) for $10 \mathrm{~h}$ and consecutively with $100 \mu \mathrm{l}$ of ExactaCruz TMC to precipitate the Gadd45a-interacting proteins (Santa Cruz Biotechnology) for $11 \mathrm{~h}$. After a series of washes, the immunoprecipitated samples were separated by SDS-polyacrylamide gel electrophoresis and visualized by Coomassie Blue staining. Protein bands with an altered expression pattern in response to the heavy metals were selected and subjected to protein identification via mass spectrometry analysis.

Pathway analysis. Molecular pathways among differentially expressed genes identified by the microarray were dissected using Pathway Studio 8.0 software (Ariadne Genomics, Rockville, MD, USA). This program integrates relevant information among imported genes, consequently allowing identification of biological pathways, gene regulation networks and protein interaction maps.

\section{Results}

Identification of molecular candidates for subchronic lowdose exposure to cadmium and nickel. The RKO cells were subchronically exposed to either cadmium chloride or nickel acetate at concentrations of 50 or $20 \mu \mathrm{M}$, respectively, for different periods of time depending on the target molecule of interest. These concentrations of the metal compounds were determined as sublethal doses and resulted in $<20 \%$ cytotoxicity $(27,28)$. Most of the genes differentially expressed by cells exposed to cadmium or nickel were HSPs, including HSP90AA1, HSP90AB1, HSPA1A, HSP90B1, HSPA2, HSPA5, HSPA8 and HSPA9 (Table I). Twenty genes were significantly altered in the cadmium-exposed cells (Table II). Interestingly, most of them overlapped with the commonly altered genes between the cadmium- and nickel-exposed cells. However, there were unique molecular networks involving the response to cadmium alone that were different from the common networks, as represented in Figs. 1 and 2, respectively. Twenty-six genes were differentially expressed in the nickel-exposed cells (Table III). Among them, several genes, including FASN, HSP90AB1, HSP90B1, HSPA5, HSPA8, KRT18 and P4HB were dysregulated both at the transcription and protein levels following nickel exposure.

Dissection of networks related to subchronic low-dose exposure to cadmium or nickel, together or alone. We also attempted to identify interactive networks among cadmiumand/or nickel-responsive genes using Pathway Studio software version 8.0. Based on a number of reliable studies, relevant components in the putative signaling pathways were chosen 
Table II. Key genes among the differentially expressed genes in cells subchronically exposed to low-level cadmium only after integrative toxicogenomic analysis.

\begin{tabular}{|c|c|c|}
\hline Gene symbol & Gene ID & Gene name \\
\hline ACTB & 60 & Actin, $\beta$ \\
\hline AKR1C2 & 1646 & $\begin{array}{l}\text { Aldo-ketoreductase family } 1 \text {, member } \mathrm{C} 2 \text { (dihydrodiol dehydrogenase } 2 \\
\text { bile acid binding protein; } 3-\alpha \text { hydroxysteroid dehydrogenase, type III) }\end{array}$ \\
\hline DCD & 117159 & Dermcidin \\
\hline HSP90AA1 & 3320 & Heat shock protein $90 \mathrm{kDa} \alpha$ (cytosolic), class A member 1 \\
\hline HSP90AB1 & 3326 & Heat shock protein $90 \mathrm{kDa} \alpha$ (cytosolic), class B member 1 \\
\hline HSP90B1 & 7184 & Heat shock protein $90 \mathrm{kDa} \beta$ (Grp94), member 1 \\
\hline HSPA5 & 3309 & Heat shock $70 \mathrm{kDa}$ protein 5 (glucose-regulated protein, $78 \mathrm{kDa}$ ) \\
\hline HSPA8 & 3312 & Heat shock $70 \mathrm{kDa}$ protein 8 \\
\hline HSPA9 & 3313 & Heat shock $70 \mathrm{kDa}$ protein 9 (mortalin) \\
\hline IDH1 & 3417 & Isocitrate dehydrogenase $1\left(\mathrm{NADP}^{+}\right)$, soluble \\
\hline KRT18 & 3875 & Keratin 18 \\
\hline MYH7 & 4625 & Myosin, heavy chain 7 , cardiac muscle, $\beta$ \\
\hline NUDC & 10726 & Nuclear distribution $\mathrm{C}$ homolog (A. nidulans) \\
\hline P4HB & 5034 & Prolyl 4-hydroxylase, $\beta$ polypeptide \\
\hline PGK1 & 5230 & Phosphoglycerate kinase 1 \\
\hline PPP1R13B & 23368 & Protein phosphatase 1 , regulatory subunit $13 \mathrm{~B}$ \\
\hline RNF128 & 79589 & Ring finger protein 128 , E3 ubiquitin protein ligase \\
\hline RPH3AL & 9501 & Rabphilin 3A-like (without C2 domains) \\
\hline TWIST1 & 7291 & Twist homolog 1 (Drosophila) \\
\hline UTS2 & 10911 & Urotensin 2 \\
\hline
\end{tabular}

and incorporated into the established networks. As a result, common biological processes disturbed by both cadmium and nickel were cell proliferation and apoptotic cell death, which can lead to neoplasms (Fig. 1). Four genes, ACTB, HSP90AA1, HSPA5 and HSPA8, were identified as main modulators in a common signaling pathway affected by cadmium and nickel. In cadmium-exposed cells, signaling networks associated with apoptosis, cell proliferation and neoplasm were affected. Several genes, BIRC3, HSPA5, HSPA8 and HSP90AA1, were revealed to be key modulators in cadmium only exposed cells (Fig. 2). Cells exposed only to nickel were associated with a unique signaling pathway related to apoptosis, cell differentiation, cell proliferation and neoplasm interacting with FASN, HSP90AA1, HSP90AB1 and JUN genes (Fig. 3).

\section{Discussion}

The mechanisms of toxicity for low-dose exposure to cadmium and nickel are unclear. Therefore, we comprehensively explored molecular candidates and the mechanisms of toxicity, both common and distinct, for both metals using integrative toxicogenomic and bioinformatic tools. Similarities and differences in gene subsets, pathways and biological processes in response to each metal are further discussed.

Using a high-resolution CGH array, we found no significant difference in recurrent $\mathrm{CNV}$ following continuous low-level exposure to both metals tested when comparing the tenth passage of the culture to the first. Less than 700 gene entities with altered expression at the mRNA and protein levels were identified by gene expression microarray and functional proteomic analysis after a 24 -h exposure to either metal individually. This small subset of genes exhibiting a very slight to mild extent of metal-induced profiling change in terms of gene structure might be attributable to the low-level metal exposure of the cells. A number of studies have reported an association between DNA copy number variation and predisposition to several genetic diseases, including cancers, neurodegenerative disorders and obesity $(29,30)$. These findings suggest that the significant contribution of a particular CNV to pathogenesis is involved in an altered dose of genes within the chromosomal region affected. Furthermore, cadmium and nickel induce carcinogenesis in diverse experimental models in vitro and in vivo. However, we found no significant alteration in recurrent CNV following low-level exposure to the metals after ten passages, suggesting that such a metal treatment has an undetectable impact on DNA structural variations based on aberrant copy number. However, exposure duration will be prolonged with such low doses in future research, as ten passages may have been insufficient for CNV to occur in p53-proficient carcinoma cells.

Alterations in gene and protein expression levels were analyzed in RKO cells following a 24-h low-dose exposure to either metals using gene expression microarray and functional proteomics, respectively. Nineteen transcripts and 69 protein entities were altered in the cadmium-exposed cells, whereas 629 transcripts and 69 protein entities were differentially expressed in nickel-exposed cells. Among them, 22 protein entities, including several members of the heat shock protein (HSP) family, were commonly altered in the cells treated with 


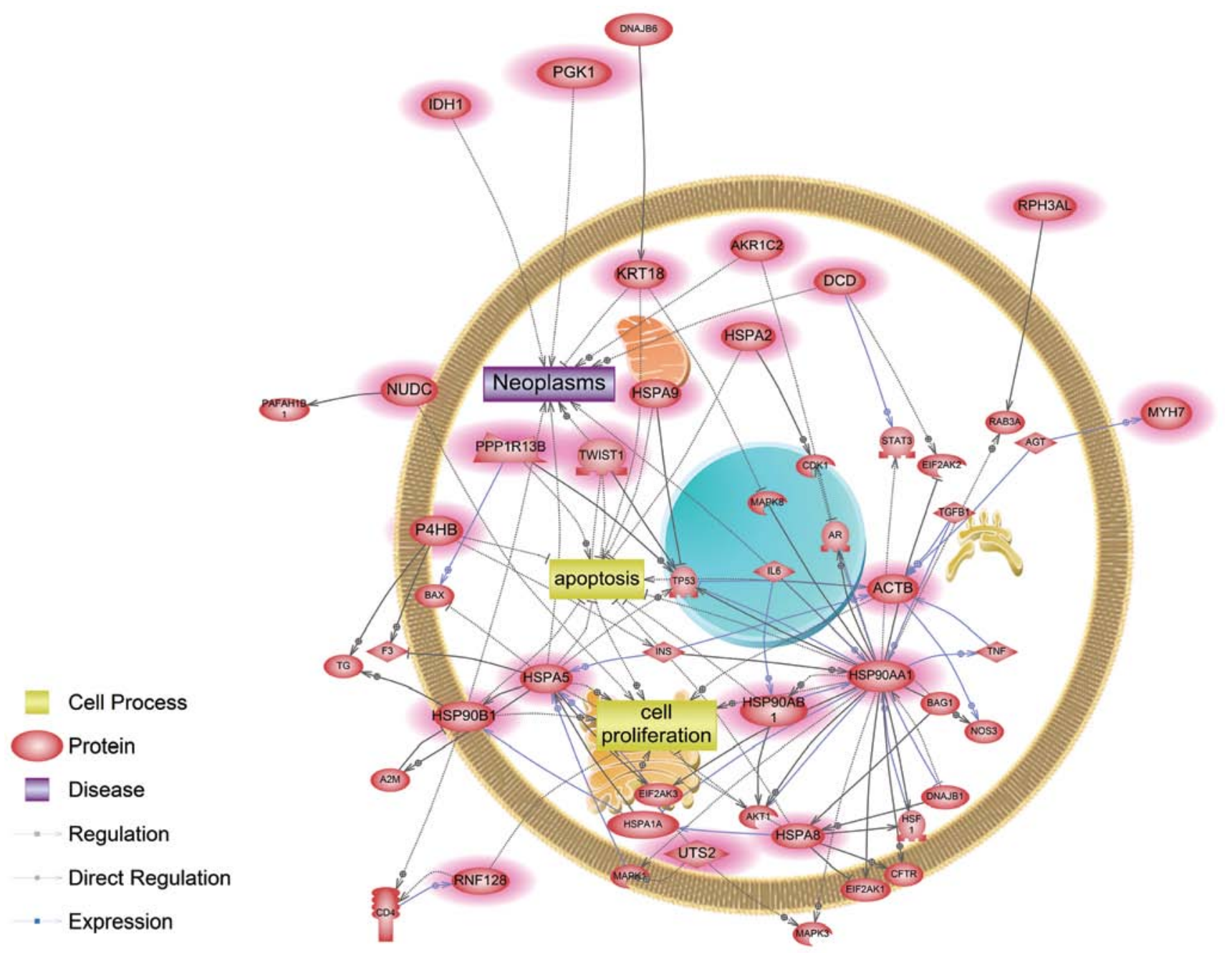

Figure 1. Representative scheme showing common interaction networks in cells subchronically exposed to low-level cadmium and nickel.

either cadmium or nickel. These proteins might be considered valuable biomarkers for cadmium and nickel exposure even at the low levels used. These entities are classified according to their functions, such as ligands (i.e., UTS2), stress proteins (i.e., ACTB, AKR1C2, DCD, HSPA1A, HSPA2, HSP90AA1, HSP90B1, KRT18 and MYH7), kinases and phosphatases (i.e., PGK1 and PPP1R13B, respectively), transcription factors (i.e., TWIST1), and other enzymes (i.e., AKR1C2, IDH1, P4HB and RNF128). Our data suggest that the molecular candidates identified here, including many regulatory factors and stress proteins, are potential metal carcinogenicity markers, which were consistently observed in previous studies (3). HSPs are stress-inducible proteins that fold and unfold other proteins and represent a suite of highly conserved and broadly distributed proteins in nature (31). HSP expression is regulated by temperature and other stressors (32). Recent studies have shown that diverse HSPs are activated by heavy metals including cadmium, copper, lead and zinc in cell lines, shrimp and the sea star $(31,33,34)$. Although our data showed downregulation of HSPs, they can be suggested as potential carcinogenesis-related genes in response to low-dose cadmium or nickel. Six genes, including AFAP1, EIF3F, FASN, HSPA1A, JUN and TRIP10 were distinct in nickel-exposed cells. Interestingly, EIF3F increased significantly in response to low-level nickel exposure. EIF3F is a protein complex with at least 13 non-identical subunits (35). The functions of the individual subunits have not been clarified; however, a recent study demonstrated that EIF3F is involved in apoptotic signaling (36). The EIF3F gene is also differentially expressed by volatile organic compounds (37); however, no reports have found a nickel-modulated signaling network involving EIF3F. Thus, these data are the first results indicating that the EIF3F gene is dysregulated by subchronic exposure to low-dose nickel and also suggest that this gene might be involved in apoptotic signaling. The FASN gene product is a key enzyme for palmitate biosynthesis into long-chain saturated fatty acids in the presence of the reduced form of nicotinamide adenine dinucleotide phosphate $(38,39)$. Additionally, this protein fuses with estrogen receptor $\alpha$ in some cancer cell lines. Another study demonstrated alterations in rat liver lipid metabolism induced by nickel deficiency (40). Thus, nickel has detrimental impacts on lipid metabolism involving FASN. JUN, a c-jun oncoprotein, is an essential component of the activator protein (AP) transcription complex. Upon heterodimerization with other Jun/Fos members, JUN forms an active AP-1 complex that regulates expression of many target genes harboring 


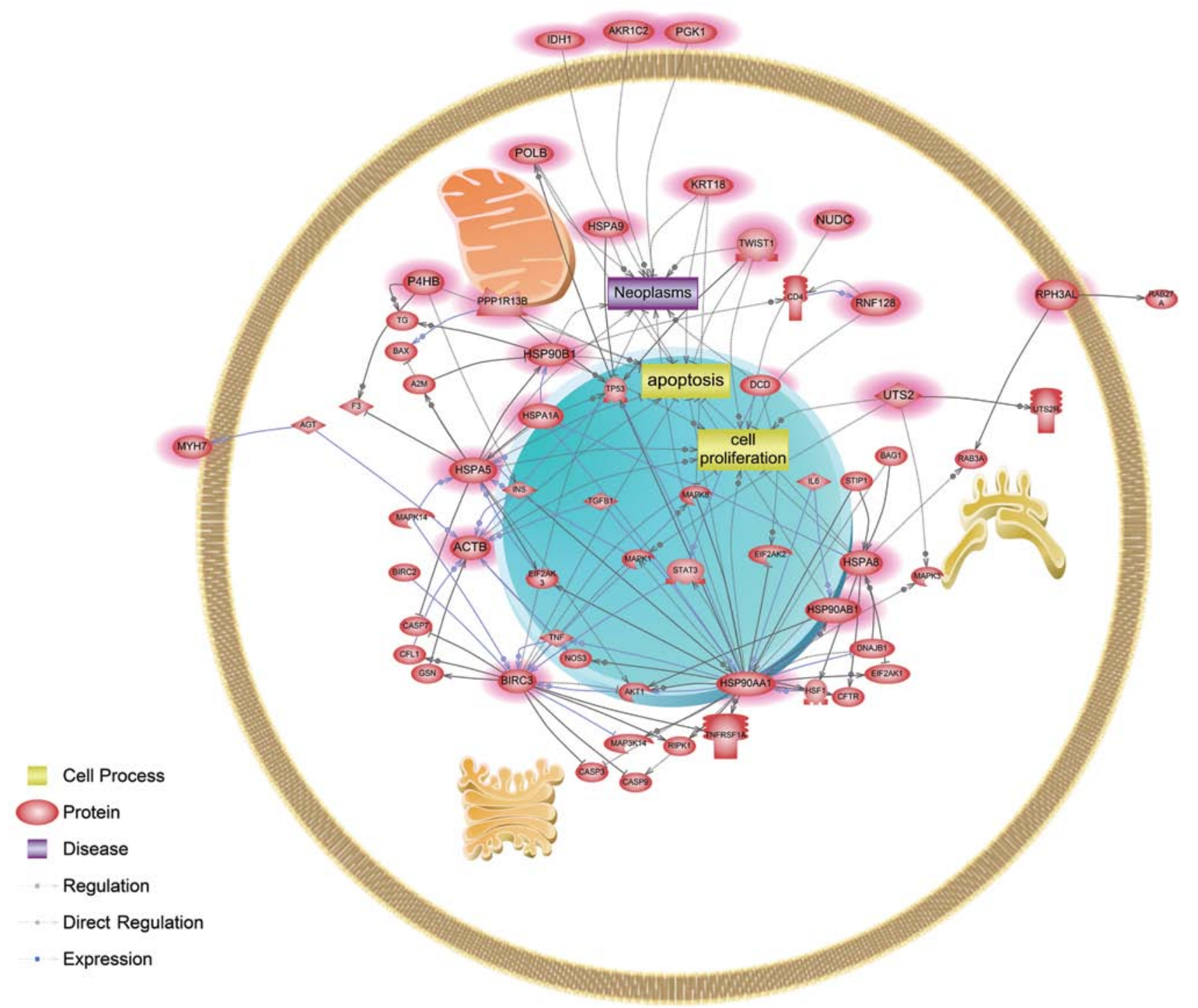

Figure 2. Representative scheme showing different interaction networks in cells subchronically exposed to only low-level cadmium.

AP-1-binding DNA elements within their promoters. These AP-1 target genes are involved in various crucial cellular functions such as cell cycle progression, migration, proliferation and apoptosis. JUN is activated upon phosphorylation by c-jun-N-terminal kinase, which responds to diverse biological stress signals (41). Interestingly, JUN both induces and inhibits cellular apoptosis (42-44).

A number of reports have demonstrated that oxidative stress, interference with cell proliferation, dysregulation of oncogenes or tumor-suppressor genes, and an impaired DNA repair system are predominant mechanisms driven by carcinogenic metal compounds $(3,45,46)$. We found that ACTB, HSP90AA1, HSPA5 and HSPA8 acted as key components of pathways associated with proliferation, apoptosis and neoplastic processes in response to cadmium and nickel (Fig. 1). The metals also interacted with important components in multiple signaling pathways crucial for cell growth, proliferation, survival, cell cycle, drug resistance, the stress response and carcinogenesis, including AKT1, BAG1, BAX, CDK1, CFTR, HSF1, TP53, MAPK3, MAPK8, STAT3 and TNF (Fig. 1). Herein, we showed that both cadmium and nickel influenced key components in the AKT1-mediated pathway, similar to a recent study showing that cadmium-induced reactive oxygen species activate the Akt/mTOR pathway by activating the positive regulator PI3K, resulting in neuronal apoptosis (47). These findings suggest that particular stressinducible proteins, protein kinases, or transcription factors may be prominent biomarkers of subchronic exposure to cadmium or nickel and may be used to develop preventive approaches for associated disorders and/or diseases; however, the underlying mechanisms of toxicity must be identified. Furthermore, targeting regulatory component crosstalk among the mitogen-activated protein kinase pathways representing a cascade of sequential phosphorylation events might offer new opportunities to develop novel anticancer agents designed to be target-specific chemotherapeutic drugs. In addition to common responses, we also examined the mechanisms of toxicity that were unique to each metal compound. Our pathway analysis results of cadmium-treated cells found that the caspase (CASP)-associated pathway was a mechanism unique to cadmium involving CASP3, CASP7 and CASP9 (Fig. 2). Gene expression changes in nickel-exposed cells were 
Table III. Key genes among the differentially expressed genes in cells subchronically exposed to low-level nickel only after integrative toxicogenomic analysis.

\begin{tabular}{|c|c|c|}
\hline Gene symbol & Gene ID & Gene name \\
\hline АСТВ & 60 & Actin, $\beta$ \\
\hline AFAP1 & 60312 & Actin filament associated protein 1 \\
\hline AKR1C2 & 1646 & $\begin{array}{l}\text { Aldo-ketoreductase family } 1 \text {, member } \mathrm{C} 2 \text { (dihydrodiol dehydrogenase } 2 \text {; } \\
\text { bile acid binding protein; } 3-\alpha \text { hydroxysteroid dehydrogenase, type III) }\end{array}$ \\
\hline DCD & 117159 & Dermcidin \\
\hline EIF3F & 8665 & Eukaryotic translation initiation factor 3 , subunit $\mathrm{F}$ \\
\hline FASN & 2194 & Fatty acid synthase \\
\hline HSP90AA1 & 3320 & Heat shock protein $90 \mathrm{kDa} \alpha$ (cytosolic), class A member 1 \\
\hline HSP90AB1 & 3326 & Heat shock protein $90 \mathrm{kDa} \alpha$ (cytosolic), class B member 1 \\
\hline HSP90B1 & 7184 & Heat shock protein $90 \mathrm{kDa} \beta$ (Grp94), member 1 \\
\hline HSPA1A & 3303 & Heat shock $70 \mathrm{kDa}$ protein $1 \mathrm{~A}$ \\
\hline HSPA5 & 3309 & Heat shock $70 \mathrm{kDa}$ protein 5 (glucose-regulated protein, $78 \mathrm{kDa}$ ) \\
\hline HSPA8 & 3312 & Heat shock $70 \mathrm{kDa}$ protein 8 \\
\hline HSPA9 & 3313 & Heat shock $70 \mathrm{kDa}$ protein 9 (mortalin) \\
\hline IDH1 & 3417 & Isocitrate dehydrogenase $1\left(\mathrm{NADP}^{+}\right)$, soluble \\
\hline JUN & 3725 & Jun proto-oncogene \\
\hline KRT18 & 3875 & Keratin 18 \\
\hline MYH7 & 4625 & Myosin, heavy chain 7, cardiac muscle, $\beta$ \\
\hline NUDC & 10726 & Nuclear distribution $\mathrm{C}$ homolog (A. nidulans) \\
\hline P4HB & 5034 & Prolyl 4-hydroxylase, $\beta$ polypeptide \\
\hline PGK1 & 5230 & Phosphoglycerate kinase 1 \\
\hline PPP1R13B & 23368 & Protein phosphatase 1 , regulatory subunit $13 \mathrm{~B}$ \\
\hline RNF128 & 79589 & Ring finger protein $128, \mathrm{E} 3$ ubiquitin protein ligase \\
\hline RPH3AL & 9501 & Rabphilin 3A-like (without $\mathrm{C} 2$ domains) \\
\hline TRIP10 & 9322 & Thyroid hormone receptor interactor 10 \\
\hline TWIST1 & 7291 & Twist homolog 1 (Drosophila) \\
\hline UTS2 & 10911 & Urotensin 2 \\
\hline
\end{tabular}

associated with a hypoxic response. Our data showed that HSP90AA1, one of the main modulators, directly interacted with hypoxia inducible factor-1 $\alpha$ (HIF-1 $\alpha)$ (Fig. 3). HIF-1 $\alpha$ is a transcription factor that induces the transcription of genes involved in glycolysis, glucose transport, apoptosis and other cellular processes as a result of a change in intracellular oxygen concentration (45). PGK1, encoding phosphoglycerate kinase 1, was found to be one of the HIF-1 $\alpha$ targets to be dysregulated in nickel-exposed cells, suggesting that nickel induces a hypoxic-like response through HIF- $1 \alpha$, which was consistent with the results of a comparative genomic expression analysis in rat liver-derived cells exposed to nickel, cadmium, or chromium (46). Dysregulation of HIF-1 $\alpha$ interferes with cellular energy metabolism, such as glycolysis, causing cells to shift toward non-oxidative forms of ATP production and altering production of glycolytic enzymes and glucose transporters (48). HSP90AA1 directly interacted with the androgen receptor (AR) based on the nickel-responsive pathway analysis. An abundance of evidence has revealed that the AR forms a heterodimer complex with Hsp90, resulting in a stable, unbound AR (49). Growth of a normal and neoplastic prostate is mediated by the AR, a ligand-dependent transcription factor activated by high affinity androgen binding. The
AR is highly expressed in recurrent prostate cancer cells. Here, HIF-1 $\alpha$ interacted with the AR in response to subchronic nickel exposure (Fig. 3). Interestingly, we also found that HSP90AA1 was involved in the BCL2-related apoptotic pathway uniquely in response to nickel exposure (Fig. 3), whereas it interacted with several CASP genes functioning in CASP-associated apoptotic signaling unique to cadmium exposure alone (Fig. 2). These data suggest that interference with the apoptotic process was likely common to both metals, but that the responsive interaction network with molecular targets was distinct in response to each metal. These findings support that HSP90 contributes to the pathogenesis of chronic diseases, including cancers, rheumatoid and arthritis, particularly through apoptosis $(50,51)$. Targeting HSP90 has emerged as a potential avenue for therapeutic intervention. HSP90 is a molecular chaperone required for the post-translational stability and function of numerous key signal transduction proteins, termed 'client' proteins $(52,53)$. A number of these client proteins have been causally implicated in the pathogenesis of prostate cancer, including AR, HER2, AKT and RAF1 (54-56). The interaction of these proteins with HSP90 regulates their half-life. We revealed from our pathway analysis that HSP90AA1 directly interacted with Src encoding Src 


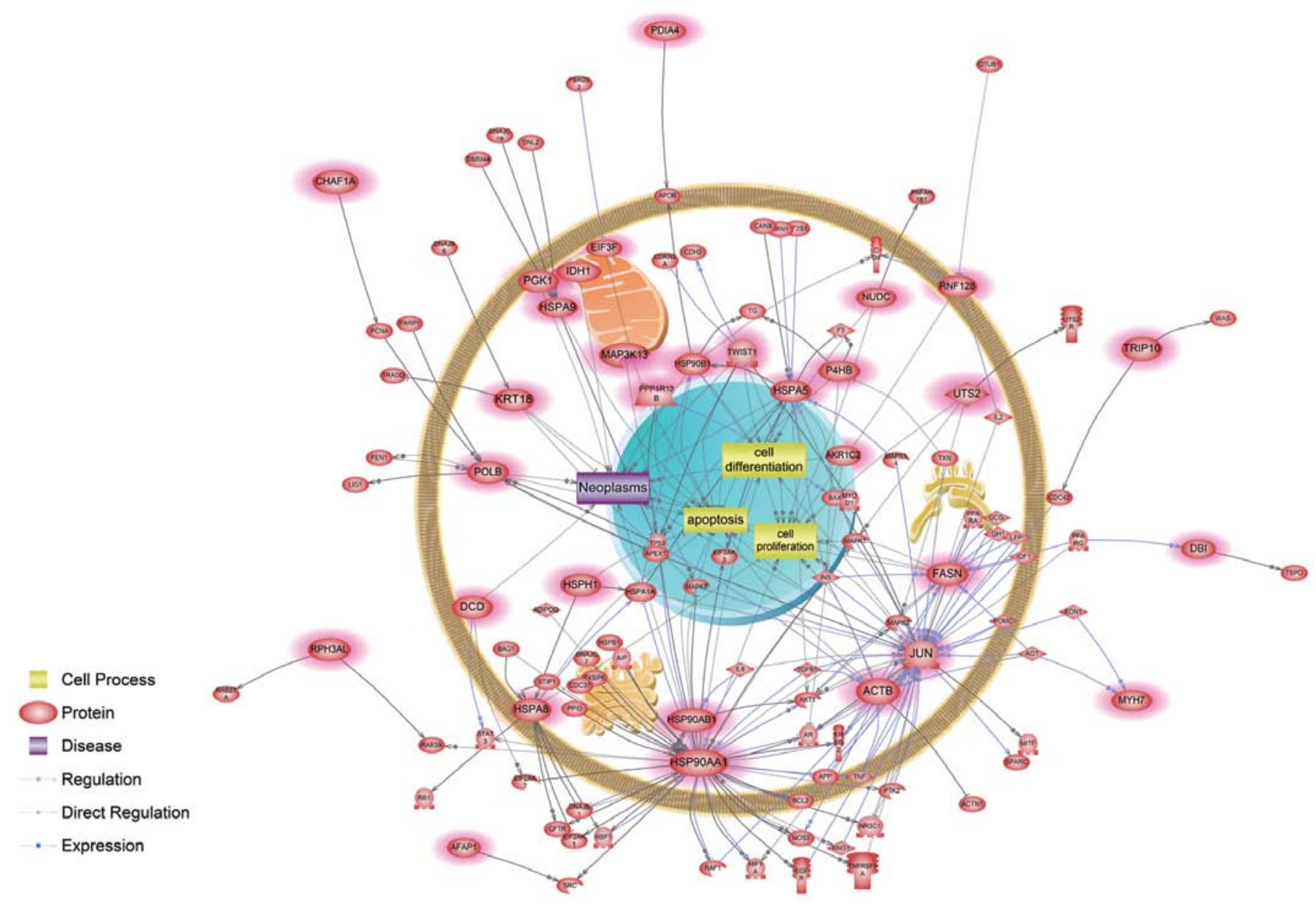

Figure 3. Representative scheme showing different interaction networks in cells subchronically exposed to only low-level nickel.

protein-tyrosine kinase. Src is a member of a large family of structurally related kinases, many of which are expressed in highly differentiated cell types $(57,58)$. Src and its family members play a key regulatory role transducing signals from cell surface receptors and coupling receptors with the cytoplasmic signaling machinery involved in several cellular processes, such as cell growth, differentiation, migration, proliferation, survival and specialized cell signaling. Additionally, JUN and FASN were shown here to be main modulators in unique nickel-responsive signaling pathways (Fig. 3) and their products have been implicated in tumor initiation and development of various tissues, as evidenced from cellular and/or epidemiological studies (59-61). JUN has a regulatory role in HIF-1 $\alpha$ function through these interactions. Stabilizing HIF-1 $\alpha$ is dependent on c-Jun domains for DNA binding and heterodimerization (62). Indeed, HIF-1 $\alpha$ is activated by interacting with c-Jun, allowing increased expression of vascular endothelial growth factor, which is a signal protein involved in stimulating vasculogenesis and angiogenesis (63). JUN was regulated by interaction with the AR. Intriguingly, JUN and FASN were also governed by interacting with AKT1, INS and LEP in nickel-responsive signaling pathways. We also found that JUN was controlled by an interaction with APEX1, a redox-sensitive repair protein that plays an essential role in the base excision repair (BER) system. Apart from APEX1, we found that many other proteins were related to the DNA damage response and DNA repair particularly in the BER pathway; FEN1, PARP1, PCNA and POLB were uniquely responsible for the nickel-associated network. JUN interacted with MITF, whose product is called microphthalmia-associated transcription factor, which has a key role in the development, survival and function of particular cell types, such as melanocytes, retinal pigment epithelial cells and osteoclasts (64). FASN was found to regulate ERBB2 or HER2 expression and vice versa. Previous studies have consistently reported FASN-mediated regulation of ERBB2 expression and a suppressive effect on ERBB2 overexpression by inhibiting FASN-encoded fatty acid synthase in cancer cells (65). Other evidence supports that ERBB2, previously identified in preneoplastic breast lesions, upregulates FASN expression (66). Furthermore, FASN overexpression increases ERBB1 or epidermal growth factor receptor (EGFR) and ERBB2 protein expression levels as well as tyrosine phosphorylation (67). Treatment of EGFR and ERBB2 with kinase inhibitors suggests that both EGFR and ERBB2 are activated by regulating EGF-mediated FASN expression (68). Interestingly, nickel seemed to uniquely perturb the cell differentiation process associated with expression and function of both common (HSP90AA1, HSP90B1, HSPA5, NUDC and TWIST1) and distinct (JUN) components (Fig. 3). This result 
suggests that although a similar subset of genes was altered upon exposure to cadmium and nickel individually, they might contribute to unique network interactions and cellular processes (Figs. 1-3). This might be attributable to the combined effects of the expression patterns and regulation of the components involved in different signaling pathways. Taken together, our results identified valuable biomarkers and distinctive signaling networks in response to subchronic lowdose exposure of carcinogenic metals cadmium and nickel.

\section{Acknowledgements}

This study was supported by Korea Ministry of Enviroment as 'The Ecoinnovation Project' (412-112-011).

\section{References}

1. Andrew AS, Warren AJ, Barchowsky A, et al: Genomic and proteomic profiling of responses to toxic metals in human lung cells. Environ Health Perspect 111: 825-835, 2003.

2. Arita A and Costa M: Epigenetics in metal carcinogenesis: nickel, arsenic, chromium and cadmium. Metallomics 1: 222-228, 2009.

3. Koedrith P and Seo YR: Advances in carcinogenic metal toxicity and potential molecular markers. Int J Mol Sci 12: 9576-9595, 2011.

4. Fabbri M, Urani C, Sacco MG, Procaccianti C and Gribaldo L: Whole genome analysis and microRNAs regulation in HepG2 cells exposed to cadmium. ALTEX 29: 173-182, 2012.

5. Talio MC, Luconi MO, Masi AN and Fernandez LP: Cadmium monitoring in saliva and urine as indicator of smoking addiction. Sci Total Environ 408: 3125-3132, 2010.

6. Martelli A, Rousselet E, Dycke C, Bouron A and Moulis JM: Cadmium toxicity in animal cells by interference with essential metals. Biochimie 88: 1807-1814, 2006.

7. Bertin G and Averbeck D: Cadmium: cellular effects, modifications of biomolecules, modulation of DNA repair and genotoxic consequences (Review). Biochimie 88: 1549-1559, 2006.

8. Hartwig A: Mechanisms in cadmium-induced carcinogenicity: recent insights. Biometals 23: 951-960, 2010.

9. Waalkes MP: Cadmium carcinogenesis. Mutat Res 533: 107-120, 2003.

10. Karin M, Haslinger A, Holtgreve $\mathrm{H}$, et al: Characterization of DNA sequences through which cadmium and glucocorticoid hormones induce human metallothionein-IIA gene. Nature 308: 513-519, 1984.

11. Schmidt CJ, Jubier MF and Hamer DH: Structure and expression of two human metallothionein-I isoform genes and a related pseudogene. J Biol Chem 260: 7731-7737, 1985.

12. Williams GT and Morimoto RI: Maximal stress-induced transcription from the human HSP70 promoter requires interactions with the basal promoter elements independent of rotational alignment. Mol Cell Biol 10: 3125-3136, 1990.

13. Hiranuma K, Hirata K, Abe T, et al: Induction of mitochondrial chaperonin, hsp60, by cadmium in human hepatoma cells. Biochem Biophys Res Commun 194: 531-536, 1993.

14. Takeda K, Ishizawa S, Sato M, Yoshida T and Shibahara S: Identification of a cis-acting element that is responsible for cadmium-mediated induction of the human heme oxygenase gene. J Biol Chem 269: 22858-22867, 1994.

15. Jin $P$ and Ringertz NR: Cadmium induces transcription of protooncogenes $c$-jun and $c$-myc in rat L6 myoblasts. J Biol Chem 265: 14061-14064, 1990.

16. Epner DE and Herschman HR: Heavy metals induce expression of the TPA-inducible sequence (TIS) genes. J Cell Physiol 148: 68-74, 1991.

17. Garcia-Morales P, Saceda M, Kenney N, et al: Effect of cadmium on estrogen receptor levels and estrogen-induced responses in human breast cancer cells. J Biol Chem 269: 16896-16901, 1994

18. Salnikow K and Zhitkovich A: Genetic and epigenetic mechanisms in metal carcinogenesis and cocarcinogenesis: nickel, arsenic, and chromium. Chem Res Toxicol 21: 28-44, 2008.
19. Doll R, Morgan LG and Speizer FE: Cancers of the lung and nasal sinuses in nickel workers. Br J Cancer 24: 623-632, 1970.

20. Kerckaert GA, LeBoeuf RA and Isfort RJ: Use of the Syrian hamster embryo cell transformation assay for determining the carcinogenic potential of heavy metal compounds. Fundam Appl Toxicol 34: 67-72, 1996.

21. Kuper CF, Woutersen RA, Slootweg PJ and Feron VJ: Carcinogenic response of the nasal cavity to inhaled chemical mixtures. Mutat Res 380: 19-26, 1997.

22. Miller AC, Mog S, McKinney L, et al: Neoplastic transformation of human osteoblast cells to the tumorigenic phenotype by heavy metal-tungsten alloy particles: induction of genotoxic effects. Carcinogenesis 22: 115-125, 2001.

23. Fletcher GG, Rossetto FE, Turnbull JD and Nieboer E: Toxicity, uptake, and mutagenicity of particulate and soluble nickel compounds. Environ Health Perspect 102 (Suppl 3): 69-79, 1994.

24. Kargacin B, Klein CB and Costa M: Mutagenic responses of nickel oxides and nickel sulfides in Chinese hamster V79 cell lines at the xanthine-guanine phosphoribosyl transferase locus. Mutat Res 300: 63-72, 1993.

25. Liao CM, Shen HH, Chen CL, et al: Risk assessment of arsenicinduced internal cancer at long-term low dose exposure. J Hazard Mater 165: 652-663, 2009.

26. Satarug S and Moore MR: Adverse health effects of chronic exposure to low-level cadmium in foodstuffs and cigarette smoke. Environ Health Perspect 112: 1099-1103, 2004.

27. Park JYS and Seo YR: The protective role of Nrf2 in cadmiuminduced DNA damage. Mol Cell Tox 7: 61-66, 2011.

28. Kim HL and Seo YR: Synergistic genotoxic effect between gene and environmental pollutant: oxidative DNA damage induced by thioredoxin reductase 1 silencing under nickel treatment. Mol Cell Tox 7: 251-257, 2011.

29. Pollack JR, Sørlie T, Perou CM, et al: Microarray analysis reveals a major direct role of DNA copy number alteration in the transcriptional program of human breast tumors. Proc Natl Acad Sci USA 99: 12963-12968, 2002.

30. Ledet EM, Hu X, Sartor O, Rayford W, Li M and Mandal D: Characterization of germline copy number variation in high-risk African American families with prostate cancer. Prostate 73: 614-623, 2013.

31. Qian Z, Liu X, Wang L, et al: Gene expression profiles of four heat shock proteins in response to different acute stresses in shrimp, Litopenaeus vannamei. Comp Biochem Physiol C Toxicol Pharmacol 156: 211-220, 2012.

32. De Maio A: Heat shock proteins: facts, thoughts, and dreams. Shock 11: 1-12, 1999.

33. Leal RB, Posser T, Rigon AP, et al: Cadmium stimulates MAPKs and Hsp27 phosphorylation in bovine adrenal chromaffin cells. Toxicology 234: 34-43, 2007.

34. Matranga V, Pinsino A, Randazzo D, Giallongo A and Dubois P: Long-term environmental exposure to metals $(\mathrm{Cu}, \mathrm{Cd}, \mathrm{Pb}$, $\mathrm{Zn}$ ) activates the immune cell stress response in the common European sea star (Asterias rubens). Mar Environ Res 76: 122-127, 2012.

35. Dong $Z$ and Zhang JT: Initiation factor eIF3 and regulation of mRNA translation, cell growth, and cancer. Crit Rev Oncol Hematol 59: 169-180, 2006.

36. Shi J, Feng Y, Goulet AC, et al: The p34cdc2-related cyclindependent kinase 11 interacts with the p47 subunit of eukaryotic initiation factor 3 during apoptosis. J Biol Chem 278: 5062-5071, 2003.

37. Yim WC, Lee MB and Kwon Y: Cross-experimental analysis of microarray gene expression datasets for in silico risk assessment of $\mathrm{TiO}_{2}$ nano-particles. Mol Cell Tox 8: 229-239, 2012.

38. Hillgartner FB, Salati LM and Goodridge AG: Physiological and molecular mechanisms involved in nutritional regulation of fatty acid synthesis. Physiol Rev 75: 47-76, 1995.

39. Smith S, Witkowski A and Joshi AK: Structural and functional organization of the animal fatty acid synthase. Prog Lipid Res 42: 289-317, 2003.

40. Stangl GI and Kirchgessner M: Nickel deficiency alters liver lipid metabolism in rats. J Nutr 126: 2466-2473, 1996.

41. Kyriakis JM: Signaling by the germinal center kinase family of protein kinases. J Biol Chem 274: 5259-5262, 1999.

42. Ham J, Babij C, Whitfield J, et al: A c-Jun dominant negative mutant protects sympathetic neurons against programmed cell death. Neuron 14: 927-939, 1995. 
43. Behrens A, Sibilia M and Wagner EF: Amino-terminal phosphorylation of c-Jun regulates stress-induced apoptosis and cellular proliferation. Nat Genet 21: 326-329, 1999.

44. Eferl R, Ricci R, Kenner L, et al: Liver tumor development. c-Jun antagonizes the proapoptotic activity of p53. Cell 112: 181-192, 2003.

45. Beyersmann D and Hartwig A: Carcinogenic metal compounds: recent insight into molecular and cellular mechanisms. Arch Toxicol 82: 493-512, 2008 .

46. Permenter MG, Lewis JA and Jackson DA: Exposure to nickel, chromium, or cadmium causes distinct changes in the gene expression patterns of a rat liver derived cell line. PLoS One 6: e27730, 2011.

47. Chen L, Xu B, Liu L, et al: Cadmium induction of reactive oxygen species activates the mTOR pathway, leading to neuronal cell death. Free Radic Biol Med 50: 624-632, 2011.

48. Gordan JD, Thompson CB and Simon MC: HIF and c-Myc: sibling rivals for control of cancer cell metabolism and proliferation. Cancer Cell 12: 108-113, 2007.

49. De Leon JT, Iwai A, Feau C, et al: Targeting the regulation of androgen receptor signaling by the heat shock protein 90 cochaperone FKBP52 in prostate cancer cells. Proc Natl Acad Sci USA 108: 11878-11883, 2011

50. Mahalingam D, Swords R, Carew JS, Nawrocki ST, Bhalla K and Giles FJ: Targeting HSP90 for cancer therapy. Br J Cancer 100: $1523-1529,2009$.

51. Hashiramoto A, Murata M, Kawazoe T, et al: Heat shock protein 90 maintains the tumour-like character of rheumatoid synovial cells by stabilizing integrin-linked kinase, extracellular signalregulated kinase and protein kinase $\mathrm{B}$. Rheumatology 50 : 852-861, 2011

52. Hahn JS: The Hsp90 chaperone machinery: from structure to drug development. BMB Rep 42: 623-630, 2009.

53. Whitesell L and Lindquist SL: HSP90 and the chaperoning of cancer. Nat Rev Cancer 5: 761-772, 2005.

54. Saporita AJ, Ai J and Wang Z: The Hsp90 inhibitor, 17-AAG, prevents the ligand-independent nuclear localization of androgen receptor in refractory prostate cancer cells. Prostate 67: 509-520, 2007.

55. Trepel J, Mollapour M, Giaccone G and Neckers L: Targeting the dynamic HSP90 complex in cancer. Nat Rev Cancer 10: 537-549, 2010.

56. Vanaja DK, Mitchell SH, Toft DO and Young CY: Effect of geldanamycin on androgen receptor function and stability. Cell Stress Chaperones 7: 55-64, 2002.
57. Parsons SJ and Parsons JT: Src family kinases, key regulators of signal transduction. Oncogene 23: 7906-7909, 2004.

58. Roskoski R Jr: Src kinase regulation by phosphorylation and dephosphorylation. Biochem Biophys Res Commun 331: 1-14, 2005.

59. Ishimura N, Amano Y, Sanchez-Siles AA, et al: Fatty acid synthase expression in Barrett's esophagus: implications for carcinogenesis. J Clin Gastroenterol 45: 665-672, 2011.

60. Beyersmann D: Effects of carcinogenic metals on gene expression. Toxicol Lett 127: 63-68, 2002.

61. Wu HC, Yang CY, Hung DZ, et al: Nickel(II) induced JNK activation-regulated mitochondria-dependent apoptotic pathway leading to cultured rat pancreatic $\beta$-cell death. Toxicology 289 : 103-111, 2011.

62. Yu B, Miao ZH, Jiang Y, et al: c-Jun protects hypoxia-inducible factor- $1 \alpha$ from degradation via its oxygen-dependent degradation domain in a nontranscriptional manner. Cancer Res 69: 7704-7712, 2009.

63. Duyndam MC, Hulscher ST, van der Wall E, Pinedo HM and Boven E: Evidence for a role of p38 kinase in hypoxiainducible factor 1-independent induction of vascular endothelial growth factor expression by sodium arsenite. J Biol Chem 278: 6885-6895, 2003 .

64. Ogihara H, Morii E, Kim DK, Oboki K and Kitamura Y: Inhibitory effect of the transcription factor encoded by the mutant $m i$ microphthalmia allele on transactivation of mouse mast cell protease 7 gene. Blood 97: 645-651, 2001.

65. Menendez JA, Vellon L, Mehmi I, et al: Inhibition of fatty acid synthase (FAS) suppresses HER2/neu (erbB-2) oncogene overexpression in cancer cells. Proc Natl Acad Sci USA 101: 10715-10720, 2004.

66. Vazquez-Martin A, Colomer R, Brunet J, Lupu R and Menendez JA: Overexpression of fatty acid synthase gene activates HER1/HER 2 tyrosine kinase receptors in human breast epithelial cells. Cell Prolif 41: 59-85, 2008.

67. Lin VC, Chou CH, Lin YC, et al: Osthole suppresses fatty acid synthase expression in HER2-overexpressing breast cancer cells through modulating Akt/mTOR pathway. J Agric Food Chem 58: 4786-4793, 2010

68. Alli PM, Pinn ML, Jaffee EM, McFadden JM and Kuhajda FP: Fatty acid synthase inhibitors are chemopreventive for mammary cancer in neu-N transgenic mice. Oncogene 24: 39-46, 2005. 